\title{
Cuidados paliativos integrales y limitación del esfuerzo terapéutico
} Global palliative care and limitation of therapeutic effort

\section{José López Castro}

S. de Medicina interna. Hospital Comarcal de Monforte de Lemos (Lugo)

Debido a la variedad de afrontamiento de la problemática al final de la vida (suicidio asistido, eutanasia, obstinación terapéutica,...) se hace imprescindible un nuevo modelo de trabajo que, sin desdeñar la autonomía del paciente ni la justicia distributiva y en aras de la mayor beneficencia, aglutine la prudente aplicación de tratamientos médicos sintomáticos con los cuidados que aporten la mayor comodidad a cada enfermo ${ }^{1}$. Junto a ello se requiere un modelo bioético que permita engarzar unos principios fundamentales "de mínimos" con los valores del individuo². Todo esto resume el abordaje integral de los Cuidados Paliativos.

La filosofía de los Cuidados Paliativos, puede resumirse en tres puntos: control de los síntomas, comunicación siempre abierta entre el paciente y el equipo de cuidadores, y apoyo emocional. Estos puntos son considerados elementos irrenunciables de cualquier programa de humanización de la asistencia sanitaria, lo que nos lleva a deducir que si alguna actividad médica tiene profundas bases bioéticas y humanizadoras, es ésta. Según la Sociedad Española de Cuidados Paliativos (SECPAL) Ios cuidados paliativos son: "Atención total, activa y continuada de los pacientes y sus allegados, por un equipo multiprofesional, cuando la expectativa de esos cuidados no incluye la curación. Ha de cubrir las necesidades físicas, psicológicas, sociales y espirituales del paciente y sus allegados. Si es preciso, debe incluir un proceso / procedimiento de asistencia al duelo". Se enfatiza la necesaria interdisciplinariedad del equipo responsable de la asistencia a unos pacientes concretos. $Y$ es que en situaciones en que el individuo se enfrenta al sufrimiento asociado al padecimiento meramente físico, el enfoque de asistencia es complejo y no exclusivamente técnico, científico o farmacológico. Mejorar las situaciones ambientales, el confort postural, la atención psicológica y el soporte emocional, con especial atención a las vivencias y sentimientos de cada persona, es imprescindible para hacer frente a la percepción próxima del final de la vida. Por eso la colaboración de psicólogos, trabajadores sociales, fisioterapeutas, enfermeras, y responsables del apoyo a las creencias espirituales, deben hallarse incluidos en la cartera de servicios de la prestación. La cooperación de los allegados, de los seres queridos es asimismo fundamental. En nuestro tiempo la oferta de los cuidados paliativos no es lo suficientemente generalizada como para que puedan beneficiarse de ella to-

\begin{abstract}
Necesitamos la vida entera para aprender a vivir, y también -cosa sorprendente- para aprender a morir.
\end{abstract}

Séneca.

dos los que tienen necesidad y derecho a su consideración ${ }^{3}$. Debe recordarse que los tratamientos curativos y los paliativos no deben excluirse los unos a los otros y aunque la instauración de cuidados paliativos se enmarque dentro de una cierta irreversibilidad, es preciso compatibilizar los esfuerzos sanadores (salvo que se haya decidido abandonarlos por completo mediante limitación del esfuerzo terapéutico p. ej. ) con los que garanticen confort y bienestar. Es decir un paciente puede estar simultáneamente con tratamiento analgésico de $3^{\circ}$ escalón y a la vez con antibiótico intravenoso para el tratamiento de una neumonía. A este respecto los programas establecidos por la SECPAL recomiendan los siguientes objetivos:

- Atención sanitaria integral y de enfoque positivo, procurando continuidad asistencial

- Garantizar integración de familiares/allegados en el proceso asistencial

- Fomentar la autonomía y dignidad del paciente

- Control de síntomas

- Generar ambiente adecuado y agradable

- Apoyo emocional y comunicación

- Preparar una adecuada aceptación de la muerte y proporcionar ayuda en el duelo

Los cuidados paliativos son una forma particular de asistencia fundamentalmente encaminada a preservar la dignidad del paciente en situación terminal, evitar la utilización fútil de recursos extraordinarios y garantizar una asistencia no maleficente encaminada a proporcionar aquellos cuidados que familia y sociedad no podrían proporcionar por sí mismos.

Desde la perspectiva de la justicia, debemos considerar que el sujeto de atención no es el paciente sino la prestación ofertada a un colectivo que no puede ignorarse, que la mejor utilización de recursos disponibles es una obligación ética de los médicos, los cuidadores, el sistema y la administración y que, de ninguna manera, la provisión de cuidados paliativos, corresponde a una "ética de máximos" (solo ofertable cuando se han cubierto los mínimos a los que todos tienen derecho). Planteándonos los aspectos en relación a beneficencia, hay que recordar el principio hipocrático por antonomasia: "Curar; y si no, aliviar; y si no, consolar", pero "A todos por igual, y a cada uno según su necesidad", conformando el pilar básico de la justicia distributiva ${ }^{4}$. 
Desde una perspectiva de Ética del Cuidado, tan frecuentemente ligada a Carol Guilligan y la ética de la enfermería, es una obligación (deber) atender a todas aquellas necesidades y funciones que el paciente no puede realizar por si mismo y procurar el confort que el paciente no puede procurarse ni mantener, evitando lesionar su dignidad. No obstante, tan importante es conocer cuándo aplicar una medida terapéutica como cuándo dejar de aplicarla o simplemente no comenzar a aplicarla.

Limitación del esfuerzo terapéutico (LET): Si intentamos relacionar la cantidad de vida conseguida en el extremo del esfuerzo asistencial con la calidad de esa misma vida, nos encontramos con una relación inversa que va desde una mínima calidad de supervivencia asociada a una obstinación terapéutica más allá de toda medida, hasta la búsqueda de una óptima calidad de vida asociada a la terminación de la misma en el momento en que al paciente le parezca más oportuno (eutanasia, ya comentada en esta sección del número anterior). Es posible comprender que el concepto de calidad de vida es exclusivamente subjetivo, que cometemos un gran error cuando opinamos sobre la vida de los demás, y que la calidad de esa subsistencia no está asociada al concepto de vida como valor absoluto, y depende sólo de quien la vive; que existen situaciones reales y concretas en que seres humanos concretos desean morir antes que seguir viviend0 ${ }^{5}$.

Existen 3 formas de LET: La primera es la que establece la limitación de instauración, de no puesta en marcha, de determinados recursos terapéuticos. La segunda es la de retirar los recursos terapéuticos puestos ya en marcha, suspenderlos. Finalmente, la tercera forma es lo que se ha llamado "acortamiento del proceso de morir", y que corresponde a la aceleración voluntaria y premeditada de una forma de vida que ya está abocada a su final en muy breve tiempo (horas). Las razones para el acortamiento del proceso de muerte suelen estar en relación con los sentimientos de angustia, dolor y disconfort de los familiares y allegados del paciente, ya que el paciente 0 está totalmente inconsciente por causas relacionadas con la enfermedad, o es mantenido en esta situación de forma farmacológica. Esta última modalidad es totalmente ilegal en nuestro país, y de hecho sólo es aceptada en los países escandinavos en base a una mayor capa- cidad de los familiares del paciente para tomar decisiones en su nombre. Algunos autores admiten una cuarta forma que es la de restricción de acceso a determinadas formas asistenciales, la más frecuente la no indicación de ingreso 0 rechazo de ingreso de un paciente concreto en una prestación determinada (Hemodiálisis, UCI, ...). Esta modalidad no deja de ser una forma de restricción o no instauración. Estas formas de limitación terapéutica suelen ser conocidas por siglas y acrónimos correspondientes a su nombre en inglés y así la no instauración o restricción es WH (de withhold), la retirada es WD (de withdraw) y el acortamiento del proceso de muerte, ilegal en España, es SDP (shorten death process).

¿Es peor retirar que no instaurar, o viceversa? La situación de LET se plantea cuando el paciente se halla en una situación en la que la inoperancia de los tratamiento propuestos va a impedir alcanzar el objetivo de conservar su vida de forma que pueda recuperar la calidad de la misma. No se plantea la LET de forma irreflexiva, se trata siempre de una indicación médica. Solo el profesional debe y puede ser consciente de los riesgos de sus esfuerzos asistenciales, del posible éxito de los mismos, del peligro de caer en una obstinación más allá de toda medida, de quebrantar los teóricos límites de la dignidad del ser humano al que atiende ${ }^{6}$. Es sólo desde esta perspectiva cuando podemos calibrar la importancia y repercusión de la medida tomada y su significación moral. Si existe indicación de LET y si el paciente está consciente y puede decidir (si no lo está, sus representantes) no existe diferencia ética entre una y otra forma de LET (WH y WD). En resumen, el facultativo en determinadas circunstancias puede proponer una LET pero el enfermo (consciente y capaz) o su representante es quien acepta o rechaza la propuesta.

\section{Bibliografía}

1. Bayés R. Morir en paz. Med Clin (Barc) 2004, 122: 539 - 541.

2. Ellershaw J, Ward C. Care of the dying patient: the last hours or days of life. BMJ 2003, 326: $30-34$.

3. López Castro J, Cid Conde L, Iglesias Rey L, Palmeiro Anta C. Cuidados paliativos: de la teoría a la práctica. Monografías Instituto Auriensis de Bioética. Ourense, 2016.

4. Bayés $R$ (moderador). Ética y sedación al final de la vida. Cuadernos de la Fundación Grifols, n 9. Fundación Victor Grifols i Lucas. Barcelona, 2003.

5. Garrido Sanjuán JA. Acortar la muerte sin acortar la vida. Pp. 70-75. Madrid, 2006.

6. Royes A. Bioética y práctica clínica: propuesta para la toma de decisiones de limitación del esfuerzo terapéutico. Rev. Calidad Asistencial 2005, 20: 391 - 395. 